\title{
A New Exploration of Roderick Usher's Death Based on the Ecological Niche Theory
}

\author{
Rongfei Wang ${ }^{1}$ \\ ${ }^{1}$ School of Foreign Languages, Zhongkai University of Agriculture and Engineering, Guangzhou, China \\ Correspondence: Rongfei Wang, School of Foreign Languages, Zhongkai University of Agriculture and \\ Engineering, Guangzhou, China. E-mail: 373572157@qq.com
}

Received: February 23, 2020 Accepted: March 31, 2020 Online Published: April 7, 2020

doi:10.5539/ells.v10n2p27 URL: https://doi.org/10.5539/ells.v10n2p27

\begin{abstract}
Roderick Usher is the protagonist of Edgar Allan Poe's masterpiece The Fall of The House of Usher. Concerning his death, the scholars and critics at home and abroad have discussed a lot but there is no fixed conclusion. Based on the ecological niche theory, this thesis explored Roderick Usher's death and concluded that his death was a natural outcome as his natural as well as his social niche positions were on the decline because of his failure to have effective communication with the environment he was living in and with the people around him. Furthermore, his niche trend to do nothing to the ever-decaying living environment but to do harm to his twin sister further accelerated the demise of his niche position. It is hoped that this thesis can shed some new light on the exploration of Roderick Usher's death and work as a kind of tentatively interdisciplinary research between ecology and literature.
\end{abstract}

Keywords: Roderick Usher's death, niche position, niche trend

\section{Introduction}

Edgar Allan Poe (1809-1849), was a celebrated poet, storyteller and literary critic in the 19th century of America. In addition to a great volume of poems and literary criticisms, Poe created altogether 70 short stories with the themes such as death, horror and grotesqueness, and therefore he was regarded as the spokesman for horror and gothic novels. The Fall of The House of Usher, a short story full of horror, gloom and death, mainly describes the death of Roderick Usher and of his sister lady Madeline and the collapse of the mansion inherited from their forefathers under the witness of the narrator "I"- - a friend of Usher's from childhood. It was collected in Tales of the Grotesque and Arabesque published in 1839 and has attracted the attention of the critics ever since. Concerning the death of the protagonist, scholars and researchers at home and abroad have explored from different perspectives, however haven't reached an agreement. Milta Nadal, from the trauma and uncanny perspective, concluded that Roderick Usher was faced with the dilemma at the heart of the traumatic experience - the desire to know and the fear of doing so, and was haunted by "memories of a remote and repressed past" (2016, p. 178) not recoverable by conscious means but which determines his present. Failure to get through trauma eventually had its toll on Usher; Tang Weisheng (2017) focused on the power of the "things" in the short story and concluded that Roderick Usher's rational thought was eroded and eventually overpowered by the ever-growing evilness of things around him, which led to his final death; Xu Dan (2007) held that Roderick Usher's death resulted from the internal fear deriving from the unbalanced development of his personality and the depressing and terrifying environment outside; Zhang Yunkai (2015) thought the ignorance of the narrator "I" also contributed to the death of Roderick Usher in addition to Usher's psychological distortion and the deteriorating environment; Zeng Xiao (2010) discussed the internal and external factors causing Usher's death and his doomed tragedy according to "the death instinct" theory; Shang Biwu (2005) argued that a series of binary oppositions such as ration and irration, the house of Usher and its owner, and Roderick Usher and his sister, underwent a simultaneous process of pairing and splitting in the short story and Usher's death was the destined result of the collapse of ration. All of these interpretations have explained Usher's death in one way or another, but just as John. H. Timmerman (2003, pp. 227-244) said: "The Fall of The House of Usher' is among those few stories that seem to elicit as many critical interpretations as it has readers", therefore the interpretation about the death of Usher will see no end. This thesis attempts to explore Usher's death based on the ecological niche position and trend theory and to provide some new insight. Through the analysis of the development of the 
position and trend of Usher as a niche in the ecosystem, it can be seen that when the niche position of Usher in the ecosystem is on the decline, and his niche trend, which refers to his influence on the environment, is diminishing, his death is doomed.

\section{The Niche Position and Trend Theory}

The concept of niche was first proposed by the American ecologist Grinnell, and in 1924, he made it clear that a niche referred to a functional relationship that biological species play in their spatial and temporal relation to the whole biological community. Therefore, the niche proposed by Grinnell was called "spatial niche". In 1927, the British ecologist Charles Elton put forward "functional niche", holding that a niche refers to the position and function a creature plays in the ecosystem. In 1957, G. E. Hutchinson put forward multidimensional and super volume niche after studying many variables, such as space and resource usage, combined the point set theory from mathematics with the abstract concept of niche. To his understanding, a niche is the assembly of the living condition for a living organism, which not only includes the spatial position of the species and its function and position in the biological community, but also its position in the environmental space. Any niche should possess two attributes, position and trend (Zhu Chunquan, 1997). Position refers to the state of a biological unit at a specific time, which reflects the interaction between past growth learning, social economy and environment. Trend means the power or influence of a biological unit on the environment. The niche of any biological unit is relative and unstable. The position and trend of a biological unit is presented by the continual interaction between itself and other biological units, and by its influence on the living environment and vice versa. In the fierce competition and due to limited resource conditions, niche expansion and compression occurs. The expansion of the niche of a species means the compression of the niche of another species in the ecosystem, resulting in the release of the resource space of a biological unit in the competition and therefore contributes to the expansion of the dominant species. Niche expansion essentially is the growth of the position and trend of biological units due to the unlimited growth potential of biological units.

According to the theory of ecological postmodernism and material ecocriticism, the whole world is a big eco-circle made up of materials and human beings are just one chain of this circle. Human beings are exchanging energy and materials with other natural species all the time. That is to say, man can be seen as an ecological niche in the whole ecosystem. It has its own position and trend as a niche in the ecosystem, and it may expand or compress with its exchange activity with other biological units and the environment. But for another respect, man is also a kind of social animal, and it also has its corresponding position and trend in the society, which can be seen as a man's social niche. From The Fall of the House of Usher, it can be seen that the protagonist Roderick Usher was in a state of fragility in the environment he was living in and he had no power or no intention to change the environment, which means that his ecological niche position is weak and his ecological niche trend is limited. Simultaneously, Usher's social niche position is quite vague for his lack of effective communication with the people around him and for the disorder of his mental state. Furthermore, his social niche trend is interwoven with some evil behaviors and accordingly his social niche position is influenced by the consequence.

\section{The Gradual Decline of Usher's Niche Position}

According to the ecological theory, it can be said that the house of Usher, Roderick Usher, his sister Madeline, the servants and the surroundings altogether constitute a kind of ecosystem, and each of them can be seen as a niche in this ecosystem. The position of Roderick Usher as an ecological niche is in sickness both physically and mentally.

\subsection{The Fragility of Usher's Ecological Niche Position}

Usher, as an ecological unit, was unable to have effective exchange with the environment due to his weak physical condition. Besides, the expansion of other species in the environment combined with the decaying environment worsened Usher's ecological niche position.

\subsubsection{Usher's Weak Physical Strength}

From the beginning of the story, we have known something about Roderick Usher's present state. In the letter sent to the narrator "I", the manuscript gave evidence of "nervous agitation", and the writer (Roderick Usher) spoke of "acute bodily illness-of a mental disorder which oppressed him" (p. 243). When "I" see Usher again, I hardly recognized him for "man had never before so terribly altered, in so brief a period, as had Roderick Usher!" (p. 245). "The now ghastly pallor of the skin, and the now miraculous luster of the eye, above all things startled and even awed me. The silken hair, too, had been suffered to grow all unheeded, and as, in its wild gossamer texture, it floated rather than fell about the face." (p. 246) From the descriptions of his skin, the luster of the eye 
and the unheeded hair, it can be seen that Roderick Usher is seriously sick and he is living just like a "wild" creature. The narrator "I" says that even with effort, he could not "connect its Arabesque expression with any idea of simple humanity." (p. 246) In the following parts, the narrator "I" was struck with Usher's "an incoherence-an inconsistency" (p. 246) arising from "a series of feeble and futile struggles to overcome a habitual trepidancy-an excessive nervous agitation" (p. 246). In addition, "His action was alternatively vivacious and sullen. His voice varied rapidly from a tremulous indecision to that species of energetic concision." (p. 246). From what "I" hear and what "I" see, from the appearance to the action, the state of Usher as a biological unit was vividly presented: he was in serious illness. Combined with the niche theory, it can be said that Usher's position as an ecological niche in the surroundings of the house of Usher is very weak. For survival, he needs to get energy or resource from the ecosystem. But the following description showed that he had lost the ability to survive in nature. "He suffered much from a morbid acuteness of the senses; the most insipid food was alone endurable; he could wear garments of certain texture; the odors of all flowers were oppressive; his eyes were tortured by even a faint light; and there were but peculiar sounds, and these from stringed instruments, which did not inspire with him." (p. 246) From the descriptions of Usher's state, it can be seen that almost all his senses are losing their functions and therefore it is almost impossible for him to get new energy and resources from the ecosystem he is in. He, as a niche, was nearly in isolation and he was in a state of self-consuming. That is to say, as a sick living biological unit with no ability to have interaction with other species or the environment, its demise is doomed.

\subsubsection{The Compression of Usher's Ecological Niche Position}

According to the niche expansion and compression theory, it is clear that the expansion of a certain species will ultimately lead to the compression of another species and even get rid of it. As what has been mentioned before, Roderick and the things around him altogether constitute a big ecosystem. In this big ecosystem, there is the "melancholy" House of Usher with bleak walls, the vacant eyelike windows, the grey sedge and the ghastly tree-stems, minute fungi and a hardly perceptible fissure, the sullen waters of the tarn. The exterior and the interior of the house, combined with the things nearby the house, all have the potential to expand if the condition permits, while Usher is in a state without the capacity to expand, therefore the compression of Usher as a biological unit in the big ecosystem is unavoidable

According to Usher, he believed in the sentience of all vegetable things. "The conditions of the sentience had been there, he imagined, fulfilled in the method of collocation of these stones - in the order of their arrangement, as well as in that of the many fungi which overspread them, and of the decayed trees which stood around - above all, in the long undisturbed endurance of this arrangement, and in its reduplication in the still waters of the tarn. Its evidence - the evidence of the sentience - was to be seen, he said, in the gradual yet certain condensation of an atmosphere of their own about the waters and the walls. The result was discoverable, he added, in that silent, yet importunate and terrible influence which for centuries had moulded the destinies of his family, and which made him what I now saw him - what he was." (p. 251) This paragraph tells us the reason for Roderick Usher's illness is that the influence from the sentience of things, but if it is analyzed from the ecological theory, especially from the words such as "overspread", "reduplication" and "the gradual yet certain condensation, it is not difficult to figure out the biological units, for example, the mungi outside the house of Usher, are expanding. Their expansion will inevitably bring about the compression of Usher because of the competition for limited resources in the ecosystem. From the word such as "the silent, yet importunate and terrible influence", "for centuries" and "moulded the destinies of his family", it can be seen that the influence of things (other biological units) around the house of Usher was enormous and everlasting and destructive to Usher's survival.

As the plot develops, it can be seen that Usher was in a more terrible state: the disappearance of his ordinary manner, the neglected or forgotten ordinary occupations, his hurried, unequal and objectless step, the assumption of a more ghastly hue of his countenance, the going out of the luminousness of his eye, and a tremulous quaver in his utterance.

In the night of the seventh or eighth day after the placing of the lady Madeline within the donjon, the narrator also experienced the full power of nervousness and he struggled to reason it off. When Usher entered with a lamp, the narrator observed that "his countenance, as usual, cadaverously wan-but, moreover, there was a species of mad hilarity in his eyes - an evidently restrained hysteria in his whole demeanour" (p. 254). Obviously, Usher was in a perishable state. What is more, the appearance of Madeline's body became the last straw on Usher. "The lofty and enshrouded figure of the Lady Madeline of Usher. There was blood upon her white robes, and the evidence of some bitter struggle upon every portion of her emaciated frame. For a moment she remained trembling and reeling to and fro the threshold - then, with a low moaning cry, fell heavily inward upon the person of her brother, and in her violent and now final death - agonies, bore him to the floor a corpse, 
and a victim to the terrors he had anticipated." (p. 259) From those descriptions, it seems that Lady Madeline is an invading species and is posing serious threat to Usher. From the words such as "fell heavily inward" and "her violent and final death", it can be understood that it is just the invasion and expansion of another species (Lady Madeline's corpse) that brings about the compression and final demise of the weak position of Usher as an ecological unit.

\subsubsection{The Harmful Influence of the Toxic and Insulated Environment}

According to the theory transcorporeality proposed by Alaimo, human beings are in the ever-changing material world and are exchanging materials such as water, air and food with other biological units all the time. This kind of material exchange has determined that all the constituents in the ecosystem are flourishing or deteriorating together. In other words, only the sound environment can ensure sound health. Conversely, if there are toxic things in the environment, then the human bodies in the process of material exchange will be toxic bodies.

From the beginning of the short story, the narrator described the environment as "a singular dreary tract of country", "with the first glimpse of the building, a sense of insufferable gloom... even the sternest natural images of the desolate or terrible", "a few white trunks of decayed trees"a black and lurid tarn that lay in the unruffled luster by the dwelling..." (p. 242) From the descriptions of the lifeless scenes around the house of Usher, it can be seen that the whole environment Usher is living in is decaying or even toxic. According to transcorporeality, the people living in a toxic environment will have toxic bodies. From this sense, Usher's body is toxic and he is doomed to die with the worsening of the environment and the release of more toxic from other species such as the ghastly tree-stems, the grey sedge, and the overspread minute fungi.

In addition to the outside environment, the house of Usher, the micro-environment that Usher is living in, cannot bring about comfort and safety for Usher. The descriptions such as "the bleak walls", the "eye-liked windows", "the Gothic archway of the hall", "many dark and intricate passages", "the carvings of the ceilings, the somber tapestries of the walls, the elbon blackness of the floors, and the phantasmagoric armorial trophies which rattled as I strode" (p. 244) can help us understand what kind of a place Usher is living in and what kind of fancies can be stirred up by those images. This can partly explain the causes for Usher's mental illness. When the narrator "I" entered Usher's room, the long, narrow and pointed windows, the black oaken floor, dark draperies, the scattered books and musical instruments and the profuse, comfortless, antique and tattered furniture were presented. The layout of Usher's room and the articles in his room kept him from interacting with the outside biological units. Without such beneficial interaction, Usher as an ecological nice has lost the opportunity to develop and expand itself. And in the room, Usher was lying on a sofa "at full length". From the posture of Usher, it seems that he was weak and in a passive and defenseless position.

From the above analysis, it is believed that the demise of Usher's ecological niche position is unavoidable, which is the result of the combination of his sick ecological niche position, his compressed ecological niche position with the expansion of other biological units in the ecosystem, and his intoxicated ecological niche position from the decaying outside environment and the insulated inside environment. Because of such a weak and fragile position of Usher as an ecological niche, he has lost its potential for expansion in the ecosystem and his demise as a biological unit is a matter of course and the selection of nature.

\subsection{The Vagueness of Usher's Social Niche Position}

It is a fact that a person is a combination of his natural attribute and social attribute. That is to say, a person has its position and trend not only in nature but also in the society. A person has to exchange substance, energy or resources with nature, but also has to develop relationships with the people in the society he is living in.

When we explore Usher's position and trend in the society he is living in, we find that his state/position in the society is distorted and retreated, and his role/trend in the society is developing in an evil way.

\subsubsection{The Gradual Collapse of Usher's Reason}

In the story, from the letter written by Usher, we can see that Usher, though suffering from mental disorder, is still have enough ration, which can be got from Usher's description of his illness and his attempt to alleviate his malady by the cheerfulness of his friend's society. What is more, the narrator's memory "his reserve had always been excessive and habitual" can also be evidence to prove Usher's ration in the past. But as the plot develops, we can see the disintegration of ration in Usher, and the irrational factor is gradually taking the upper side. After the reunion of Usher and the narrator "I", I was not only struck by the dramatic change of Usher's appearance, but also by Usher's inconsistency which arose from "a series of feeble and futile struggles to overcome a habitual trepidancy - an excessive nervous agitation" (p. 246). Usher himself also admitted that he must "abandon life and reason together" (p. 246), in some struggle with fear. And the narrator also learned that Usher 
was enchained by certain superstitious impressions in regard to the dwelling which he tenanted. From those descriptions, it is clear that Usher's reason is on the way to breaking down. Reason is usually opposite to sentiment and imagination. While during my stay with Usher, "We painted and read together; or I listened, as if in a dream, to the wild improvisations of his speaking guitar." (p. 248) Those practices of painting, reading or composing music usually involve more sentiment than reason. From the words and expressions such as "in a dream" and "wild improvisations", it can be seen that Usher's reason was discarded to some extent. The narrator also held that it was futile to cheer "a mind from which darkness, as if an inherent positive quality, poured fourth upon all objects of the moral and physical universe, in one unceasing radiation of gloom." (p. 248) It can be seen that Usher's mind was the source of the pouring of "darkness" in one "unceasing radiation" of gloom, which has no place for reason. From the small picture, the verses and the books they read, Usher's loss of reason was vividly presented. In the small picture of the vault or tunnel, there is "no torch, or other artificial source of light, was discernible." (p. 248) The picture a person draws usually reflects the drawer's mind. The absence of torch or other artificial source of light is just the reflection of the absence of reason in Usher's mind. From the verses 'The Haunted Palace', the narrator perceived a full consciousness on the part of Usher, "of the tottering of his lofty reason upon her throne." (p. 249) Furthermore, in the train of thought rising from the verses, Usher's opinion was that "in its general from, was that of the sentience of all vegetable things." (p. 251) His reason was not taking a position here. The books they are reading have formed "no small portion of the mental existence of the invalid" (p. 251) and are "in strict keeping with this character of phantasm" (p. 251). Without doubt, these books will exert great influence on Usher and expel reason from his mind gradually.

As the plot develops, Usher encoffined his sister and entombed her corpse in a vault "small, damp, and entirely without means of admission for light". (p. 252) This incident indicated that the collapse of his reason was developing further because he had done something evil for lack of reason. With the gradual disintegration of Usher's reason, his niche position in the reality will be weaker and weaker.

\subsubsection{Failure to Establish Sound Social Relationships}

According to Marx, man is the sum of all social relationships. Man recognizes his own existence through others and can only know himself through interacting with others. But the relationships of Usher were not sound.

\subsubsection{Usher's Indifferent Relationship with the Narrator "I"}

In the short story, the narrator "I" describes his accompany with Usher. According to the narrator, Roderick had been one of his boon companions in boyhood; but many years "had elapsed" since their last meeting. The letter written by Usher expressed Usher's desire to see the narrator, "as his best, and indeed his only personal friend" to alleviate his own malady by the cheerfulness of the narrator's society. From this, it can be seen that Usher has not formed enough relationship in the society, and it seems that his calling to the narrator is a little practical. He desired to see the narrator just because he wanted his illness alleviated. And for the narrator's part, although he went to the house of Usher without much room for hesitation, he still considered it as a very "singular summons." Then the narrator admitted that he and Usher "had been even intimate associates" as boys, yet he actually knew little of his friend. So, it seemed that the narrator's visit was more out of his curiosity than out of his care. Upon his entrance, Usher arose from the sofa and greeted him with "a vivacious warmth", but the narrator thought there was much of "an overdone cordiality — of the constrained effort of the ennuye man of the world." (p. 245) All the evidence shows that there is no much mutual understanding between Usher and "I". Their different roles are dislocated to some extent, and their relationship is not so warm as they have thought or defined. As the plot develops, it can be seen that the narrator's society in fact doesn't alleviate Usher's illness, rather, it worsens the condition of Usher. What's more, the narrator also realized that he couldn't help Usher out of his malady. "the futility of all attempts at cheering a mind from which darkness, as if an inherent positive quality, poured forth upon all objects of the moral and physical universe, in one unceasing radiation of gloom." (p. 248) When Usher claimed to preserve lady Madelin's corpse for a fortnight in one of the numerous vaults, the narrator didn't stop Usher's abnormal and irrational behavior but as a matter of fact he had become the conspiracy of Usher. In the night of the seventh or eighth day after the placing of the lady Madeline, the narrator also experienced a feeling of terror and when Usher with "a species of mad hilarity in his eyes - an evidently restrained hysteria in his whole demeanour" (p. 254) came for help, the narrator chose to read the antique volume 'Mad Trist' hoping to relieve the extreme excitement. But according to the contents of "Mad Trist', we can know that such a book will not be a relief, rather, it is a kind of stimulus which will arouse more excitement or terror in Usher, which is quite destructive to Usher at that moment. According to the analysis above, it can be seen that the function of the narrator "I" wasn't fully played. The narrator didn't alleviate Usher's malady, instead, he aided Usher's abnormal behaviors and stimulated Usher's malady to some extent. Therefore, Usher's attempt to seek for help from "his only friend" failed, and his delicate state can't be changed. What is more, the narrator as Usher's only friend also 
indicated that Usher occupied limited human resources, which was another evidence to show that Usher's niche state was very delicate and he hadn't formed solid social relationships. Without solid social relationships, the development of a person's niche state will be curbed.

\subsubsection{Usher's Abnormal Relationship with His Sister Madeline}

Concerning the relationship between Usher and Madeline, scholars have posed different interpretations. Certain scholars such as Ge Jihong (2000) and Luo Deqiong (2011) held that there was an incest relationship between the twins, but it was not fixed. One point that the twin's relationship is strange or abnormal is for sure. Though they were twins, there was no intimacy or communication between them from the text. Instead, indifference and unfathomable conflicts existed between them. On one hand, Usher stated with unforgettable bitterness that his gloom could be traced to the severe and long-continued illness of his tenderly beloved sister, "his sole companion for long years - his last and only relative on earth." And her decease would leave him the last of the ancient race of the Ushers. It seemed that he really cared much about his sister. But it was a little strange that "for several days ensuing, her name was unmentioned by either Usher or myself." (p. 247) And the narrator "I" was informed abruptly of the death of Lady Madeline (who was actually en-coffined alive) and was told of Usher's intention of preserving her corpse for a fortnight in one of the numerous vaults. On the surface, Usher loved her sister and was unwilling to let her go; but in fact, he entombed his sister's encoffined body into a room which is "small, damp and entirely without means of admission for light". (p. 252) And the vault had been used "for the worst purpose of a donjon-keep" (p. 252), and the door of massive iron had been protected and its immense weight caused an "unusually sharp grating sound" (p. 252). Such a place actually could by no means a place for people to rest in peace. It was more like a prison than a tomb. It can be seen that Usher had tried every effort to stop his sister get out of this prison. The relationship between the twins is really strange and weird. With the development of the plot, we know Usher has been in a state of terror for encoffining his sister and has been in a state of extreme agitation, which prepared for his final death.

In addition to what have been said above, other kinds of relationship presented are also quite abnormal. When the narrator "I" arrived at the house of Usher, "a valet, of stealthy step, thence conducted me, in silence, through many dark and intricate passages in my progress to the studio of his master." (p. 244) And the countenance of the family's physician "wore a mingled expression of low cunning and perplexity" (p. 245). The physician accosted me "with trepidation and passed on" (p. 245). All these showed that the indifference and absence of Usher's interpersonal relationships.

Usher never going out of the house of Usher, plus the indifferent relationship with the people around him, rendered him a reclusive and isolated life, which is not helpful to alleviate his gloom. It can be said that "the absence of friendship, unhealthiness of kinship and the bleakness of love are the reasons for Usher's doom." (Yechao, 2005, p. 107)

According to Zhu Chunquan (1997, p. 324), the "ecostate" (niche position) of the bilogical unit is the accumulated result of growth and development, learning, socio-economical development and the interacting with surrounding environment in the past." Combined with the situation of Usher: the decline of his physical strength, the loss of his reason, the inability to communicate effectively with the environment and the people around him, it can be seen that Usher's ecostate is very weak and fragile. It has lost the driving force and potential in itself for development and expansion. According to Li Guangyao (2008), ecostate is the basis, while the storage of ecorole can increase the transformation capacity of ecorole. That is to say, even the ecostate is weak or fragile, but if the ecorole is developing in a healthy way, it is possible to change the ecostate. The next part will focus on the analysis of Usher's ecorole.

\section{The Futility of Usher's Niche Trend}

According to the niche theory, we know that the ecorole refers to the current effects on the environments, such as the rate of energy and matter exchange, productivity, growth rate, economic development and expanding rate for new space, etc. That is to say, a person's influence on the natural environment and social environment is the specific manifestation of his niche trend, and simultaneously is the inner desire and requirement of a normal person. But Roderick Usher is by no means a normal person for his influence on the environment is nearly nothing and his influence on other people is taking an "evil" trend which can exert influence on his niche state reversely.

\subsection{Usher's Powerlessness to the Environment}

From the very beginning, the narrator " $\mathrm{I}$ " described the bleak scenes around the House of Usher and felt a sense of insufferable gloom pervading his spirit, which was caused by "combinations of very simple natural objects". 
The narrator reflected that it was possible that "a mere different arrangement of the particulars of the scenes, of the details of the picture, would be sufficient to modify, or perhaps to annihilate its capacity for sorrowful impression" (p. 242). But according to the descriptions of the story, we can see that Usher, as the owner of the House of Usher, didn't make any alteration to the environment. That is to say, his niche trend didn't give full play because he didn't exert any influence on the environment. Without his influence, the living things in the environment are developing in their own way and are gaining more energy and substance transfer from the environment which in a way will impact the living state of Usher. What is more, the principal feature of the House of Usher was "that of an excessive antiquity", and the great "discoloration of ages", "the overspreading of minute fungi", "a barely perceptible fissure", "many dark and intricate passageways", "the long, narrow and pointed windows", "the dark draperies", etc. showed that Usher didn't change any part of the House of Usher whose layout and decoration actually contributed to "heighten the vague sentiments". Just because Usher's exerting on influence on the antique and isolated House of Usher, the living environment for him is shrouded by gloom, decay and even death, which will bring about harm effects on his living state. It can be seen that with the powerless niche trend, Usher's niche position was influenced by his living environment in a harmful way with his health further deteriorating, his reason gradually collapsing and his personality eventually divided.

\subsection{Usher's Harmful Influence on the People Around Him}

The niche trend of a person can also be reflected on his or her influence on other people. In the novel, it can be seen that Roderick was influencing the narrator "I" and his sister Madeline in a harmful way by his confusion and malady.

\subsubsection{Usher's Influence on the Narrator}

The narrator "I" was quite a reasonable person when he paid a visit to Usher though he felt gloomy, oppressive or shocked at the sceneries and the great changes on Usher. With spending more and more time with Usher, the narrator was influenced by Usher step by step. The narrator's ears echoed Usher's long improvised dirges and he held "painfully in mind a certain singular perversion and amplification of the wild air of the last waltz of Von Weber"; he shuddered at the vagueness of Usher's paintings which Usher's "elaborate fancy" brooded over; he felt "an intensity of intolerable awe" arising out of the pure abstractions which Usher contrived to throw upon his canvas. From the examples above, it is not difficult to see Usher's influence on the narrator. The narrator was more and more in a state of fear and awe. After the narrator aided Usher to bury Madeline in one of the vaults, not only was Usher's mind unceasingly agitated, the narrator "I" was greatly influenced by Usher's state. "It was no wonder that his conditions terrified - that it infected me. I felt creeping upon me, by slow yet certain degrees, the wild influences of his own fantastic yet impressive superstitions." (p. 253) It seemed that the narrator's reason was gradually collapsing under the influence of Usher's malady and fear. The narrator was even obsessed with allusion when he read 'Mad Twist' for Usher. "No sooner had these syllables passed my lips, than - as if a shield of brass had indeed, at the moment, fallen heavily upon a floor of silver." (p. 256). Fortunately, the narrator managed to escape from the House of Usher because of his remaining reason and the demise of Usher and Madeline altogether. But the influence on him will be far-reaching and the harmful effects will not be easy to be removed.

\subsubsection{Usher's Influence on Madeline}

Usher's Influence on his sister Madeline is mainly reflected in his burying Madeline alive. Usher informed the narrator of the death of Lady Madeline "abruptly" and intended to preserve her corpse for a fortnight and placed the en-coffined body in one of the numerous vaults, which was small, damp, and entirely dark and was used as a donjon-keep in remote feudal times. Besides, the whole interior of a long archway was "carefully sheathed with copper" and the massive iron door was "similarly protected". From those descriptions, we can see that Usher not only buried Madeline and placed her body in a place from which it was impossible for her to escape. He exerted his evil power on his sister and his ecorole took the evil trend. What is worse, he didn't make up for his wrongdoings even when he heard "her first feeble movements in the hollow coffin". When at last the "lofty and enshrouded figure of the Lady of Madeline appeared, with blood on her white robes, and the evidence of bitter struggle upon every portion of her emaciated frame" (p. 259), she felt "heavily inward upon the person of her brother, and in her violent and now final death-agonies, bore him to the floor a corpse, and a victim to the terrors he had anticipated." (p. 259) It can be said that Usher was terrified to death because what his ecorole has done returned the influence to himself and finally led to his death.

\section{Conclusion}

Through analyzing Usher's niche position and trend, it can be seen that his niche position was very weak and fragile which mainly resulted from his extremely poor physical strength, the loss of his reason, the failure to 
establish normal social relationships. Besides, His niche trend either plays no part in influencing his environment or influencing the environment in an evil way, which will further deteriorate his niche position. In the ecosystem around Usher, Usher's niche took up a very small percentage and was in a state of no more growth. Niche expansion is the momentum of the development and evolution of the biosphere and the instinct characteristics of a living system, which results from the infinite increase of position and trend of a certain niche. From the above analysis, it can be seen that Usher's niche has lost the inner momentum for growth and development and its retreat or even death will be a doom. That is to say, Usher's death is the result of the withering and vanishing of his niche. From the niche theory to analyze the death of a protagonist in the short story can be seen as a tentative attempt, hoping to shed some new light on the interpretation of characters. Simultaneously, by regarding Usher as a niche, it is beneficial to raise people's awareness to see mankind as one part of the big ecosystem and not to regard man as the center of everything any longer.

\section{References}

Ge, J. H. (2000). A New Interpretation of The Fall of the House of Usher. Journal of Hainan University, 18(02), $73-76$.

John, H. T. (2003). House of Mirrors: Edgar Allan Poe's The Fall of the House of Usher. Papers on Language and Literature, 3, 227-244.

Li, G. Y. (2008). Summary of Niche Theory and Its Application prospects. Anhui Agricultural Science Bulletin, 14(7), 43-45.

Nadal, M. (2016). Trauma and the Uncanny in Edgar Allan Poe's "Ligeia" and "The Fall of the House of Usher". The Edgar Allan Poe Review, 17(2), 178-192. https://doi.org/10.5325/edgallpoerev.17.2.0178

Shang, B. W. (2005). On "The Fall of the House of Usher". Henan University of Science and Technology (social sciences), 23(04), 63-66.

Tang, J. N. (2016). Material Ecocriticism: The Material Turn in Ecocriticism. Contemporary Foreign Literature, $2,114-121$.

Tang, W. S. (2017). Adgar Allan Poe's “Thing” Narrative: Re-Reading The Fall of the House of Usher. Foreign Language and Literature, 33(3), 6-11.

Xu, D. (2007). The Fear of Heart and the Depression of the Environment: On the Tragedy of the Protagonist in The Fall of the House of Usher. Journal of Social Science of Hunan Medical University, 9(04), 110-112.

Ye, C. (2005). Doomed Tragedy: Psychoanalysis of Roderick Usher in Edgar Allan Poe's The Fall of the House of Usher. Journal of Anhui Normal University (Hum. and Soc. Sci.), 33(01), 105-109.

Zeng, X. (2010). The Cellar to Bury Self: An Analysis of the Tragedy of the Protagonist in The Fall of the House of Usher. Journal of Shanxi Normal University (Social Sciences), 11, 48-49, 52.

Zhang, Y. K. (2015). Who is to Blame for Roderick's Death: Close Reading of Adgar Allan Poe's The Fall of the House of Usher. Journal of Language and Literature Studies, 10, 68-69, 121.

Zhu, C. Q. (1997). The Niche Ecos at e-ecorole Theory and Expansion Hypothesis. Acta Ecologica Sinica, 17(3), 324-332.

\section{Note}

All the quotes of The Fall of the House of Usher are taken from The Collected Tales \& Poems of Edgar Allan Poe with Illustrations by Harry Clarke, Wordsworth Library Collection, 2017.

\section{Copyrights}

Copyright for this article is retained by the author, with first publication rights granted to the journal.

This is an open-access article distributed under the terms and conditions of the Creative Commons Attribution license (http://creativecommons.org/licenses/by/4.0/). 